\title{
DE KANT A FREUD: A SOCIABILIDADE INSOCIÁVEL DA HUMANIDADE
}

\author{
Josiane Magalhães ${ }^{1}$ \\ Marcelo L. G. Beck ${ }^{2}$
}

\begin{abstract}
1 Josiane Magalhães é professora de Sociologia da UNEMAT - Universidade do Estado do Mato Grosso e pós-graduanda em Educação, nivel de mestrado pela Unesp - campus de Marilia.

${ }^{2}$ Marcelo Luis Grassi Beck é Psicólogo, pós-graduando em Psicologia, nível de mestrado pela Unesp - Campus de Assis.
\end{abstract}

Este texto tem como proposta demonstrar a proximidade dos pressupostos kantianos e freudianos no que se refere à argumentação sobre a necessidade de associação dos seres humanos contrapostos a uma insociabilidade inerente à natureza humana. $\mathrm{O}$ ponto de partida para as reflexões que se seguem tratam especificamente de uma análise do texto "Idéia de uma história universal de um ponto de vista cosmopolita" de Imanuel Kant e "O mal-estar na civilização" de Sigmund Freud.

\section{AS PROPOSIÇÕES KANTIANAS}

$\mathbf{E}$ m seu texto "Idéia de uma história universal de um ponto de vista cosmopolita", Kant inicia suas argumentações esclarecendo alguns dos pontos fundamentais em que estas são alicerçadas.

O primeiro ponto está na definição dos atos humanos, os quais são considerados como as "manifestações fenomenais" da liberdade da vontade humana, sendo determinados por leis naturais de caráter universal.

Após, define a história como sendo aquela ciência que se ocupa da narração destas manifestações, a qual deve levar em consideração o jogo da liberdade da vontade humana em sua generalidade, para que, assim, venha poder descobrir um curso regular dessas manifestações e compreender aquilo que nos parece confuso e irregular nos indivíduos isolados. Estas manifestações devem ser consideradas como um desenvolvimento contínuo, embora lento, das capacidades originais no conjunto da espécie humana.

Considera ainda, que os homens não agem meramente por instinto, nem tampouco como cidadãos racionais do mundo segundo um plano determinado. Isto porque, os indivíduos parecem "entretecidos de loucura, vaidade pueril, infantil maldade, sede de destruição, e ainda orgulhosos de sua superioridade." (KANT, 1974)
Desta forma, os atos perversos da humanidade são os mais marcantes na consecução do texto histórico. Por conta disso, um filósofo não conseguiria pressupor um específico propósito racional em cada indivíduo, o que seria subjetivo a este.

Assim, a primeira proposição a que Kant chega é a de que "todas as disposições naturais duma criatura estão destinadas a desenvolver-se um dia de maneira plena e adequada ao respectivo fim" a qual se acrescenta a segunda proposição, "no homem ( única criatura racional existente na Terra) aquelas disposições naturais que se destinam ao uso de sua razão só viriam a desenvolver-se plenamente na espécie e não no indivíduo"

Aqui está posta a primeira noção que marca todo o raciocínio de Kant, a saber: a idéia de progresso. Este progresso seria o objeto da história, no sentido de descrever as manifestações fenomenais da vontade humana, ou seja, os atos humanos, guiados por um fio condutor. Este claramente é considerado como sendo o desenvolvimento das disposições naturais ( determinadas pela natureza), que no homem, enquanto espécie, considera-se as que se destinam ao uso da razão.

A terceira proposição é uma confirmação das duas anteriores, pois "a natureza quis que o homem tire inteiramente de si próprio tudo aquilo que ultrapassa a ordenação mecânica da sua existência animal, e que não 
participe de qualquer outra felicidade ou perfeição além daquelas que ele possa agenciar independentemente do instinto, através de sua própria razão".

É curioso notar como Kant resolve a questão entre os desígnios da natureza e a fundamentação do desenvolvimento humano em si mesmo. isto porque coloca a natureza como determinante do sentido da existência humana. No entanto, as disposições naturais do homem fundam-se em sua razão, a qual permite-lhe "elevar-se da extrema crueza dessa existência", puramente instintiva, animal, "até a habilidade máxima, à perfeição interna de sua maneira de pensar". Os limites entre homem e natureza estão postos pela razão. Esta é dada ao homem pela natureza e deverá ser utilizada por ele juntamente com sua "liberdade de vontade", que na própria razão se funda, para o desenvolvimento humano e consequentemente o progresso da espécie até atingir a felicidade. Esta última seria conseguida somente pelas últimas gerações.

Prosseguindo seu raciocínio, Kant nos mostra o que para ele seria o motor da história em sua quarta proposição: "O meio de que a natureza se serve para levar a cabo o desenvolvimento de todas as suas disposições naturais é o seu antagonismo dentro da sociedade, na medida em que este antagonismo acaba por se tornar a causa de uma ordenação regular dessa mesma sociedade."

Retomemos o fio condutor de suas argumentações. A natureza dá ao homem a razão para que este através daquela e de sua liberdade de vontade, desenvolva suas disposições naturais, as quais também são determinadas pela natureza, progredindo de maneira lenta e gradual. Nesta proposição, Kant acrescenta a idéia do antagonismo interno da sociedade, o qual levaria os homens ao seu desenvolvimento. Este antagonismo seria a "sociabilidade insociável dos homens, isto é, sua tendência para entrarem em sociedade, que todavia anda ligada a uma resistência que a todo momento ameaça dissolver essa sociedade". O mecanismo desse antagonismo seria movido da seguinte forma: associando-se, o homem sente o desenvolvimento das suas disposições naturais, que corresponde ao progresso humano. No entanto, possui uma tendência a se isolar, porque encontra em si, ao mesmo tempo, a particularidade 'insociável" de querer dirigir tudo somente de acordo com seu desígnio, ou seja, através da sua liberdade de vontade. É precisamente essa resistência que desperta todas as forças humanas as quais fazem os homens superar a preguiça, a ambição, o instinto de domínio e cobiça para progredir.

Até este ponto Kant expõe sua compreensão acerca da natureza humana e da relação estabelecida entre homem, natureza e progresso. Daqui por diante, concebe hipóteses de como o desenvolvimento humano caminhará. A quinta proposição expressa essa idéia: "O maior problema da espécie humana, a cuja solução a natureza força o homem, é o estabelecimento duma sociedade civil, que administre universalmente o direito".

Vimos anteriormente que o homem se associa aos outros para sentir o desenvolvimento de suas disposições naturais e que sua liberdade gera o antagonismo, o qual imputa-lhe a tendência a se isolar. A discussão realizada nesta proposição segue no sentido de colocar uma solução para este antagonismo. Isto porque ao construir uma sociedade civil que administre universalmente o direito, os homens terão o ambiente necessário para o desenvolvimento de suas disposições. Ao mesmo tempo, através da administração universal do direito, os homens elaborariam uma Constituição civil justa através da qual haveria a mais rigorosa determinação e garantia dos limites da liberdade individual para a coexistência com a liberdade dos outros. Desta forma, o antagonismo gerado pela tendência humana a se isolar alcançaria um patamar de coesão onde a tarefa máxima posta pela natureza à espécie humana - o desenvolvimento de suas disposições naturais - seria alcançada. A constituição civil justa possibilitaria a criação desta sociedade onde a liberdade estaria submetida a leis externas irresistíveis.

A sexta proposição pode ser considerada como um desdobramento do problema posto na quinta proposição. "Este problema é simultaneamente o mais difícil e o que mais tardiamente é resolvido pela espécie humana. A dificuldade, que a simples idéia desta tarefa faz logo ressaltar, é a seguinte: o homem é um animal que, quando vive entre outros da sua espécie, precisa de um senhor"

A explicação para o problema é dada da seguinte maneira: o homem faz mau uso de sua liberdade em relação aos outros, pois possui uma tendência animal e egoísta. Isto leva-o a se constituir exceção à lei. Esta condição gera a necessidade de alguém ( um senhor) que o obrigue a obedecer uma vontade universalmente válida ( a Constituição). Se esse senhor é buscado na própria espécie, ele também irá precisar de um senhor, pois tem a mesma tendência animal e egoísta. Seja este senhor um único elemento ou vários, haverá sempre a necessidade de alguém que exerça uma pressão sobre os mesmos para que a lei seja obedecida. Além disso, para que esse problema da exceção à lei se resolva, necessita-se de "conceitos corretos sobre a natureza duma constituição possível, ter uma larga experiência, grande prática dos rumos do mundo, e, sobretudo, boa vontade preparada para aceitar essa constituição".

Nesse ponto, Kant nos concede a argumentação necessária para que se conceba um estado coercitivo, uma vez que a tendência animal e egoísta é inerente à espécie humana. Além disso, nos apresenta aquilo que considera essencial ao líder ou líderes que se incumbirão de governar a sociedade constituída ${ }^{3}$.

A partir da sétima proposição, Kant desenvolve o cosmopolitismo de sua proposta, ou seja, percebe as relações humanas em seu todo. "O problema do estabelecimento de uma constituição civil perfeita depende do problema das relações legais externas entre os estados, e não pode ser resolvido sem se encontrar a solução deste segundo."

Para o autor o mesmo antagonismo existente na constituição de uma sociedade humana, aparece também nas relações que se estabelecem entre sociedades diferentes. A

\footnotetext{
${ }^{3}$ Essa referência nos permite também, concluindo para além do texto kantiano, que o autor abre a possibilidade de uma reflexão no sentido de perceber os próprios governantes usando do poder instituído em benefício próprio, uma vez que podem constituir-se exceção à lei.
} 
mesma argumentação colocada para solucionar o antagonismo no interior da sociedade, a saber: a compleição de uma constituição civil que é o poder irresistível que une os indivíduos, garantindo a liberdade através da imposição de seus limites, é proposta para solucionar a questão entre as diferentes sociedades. Estas devem realizar acordos comuns, que no conjunto geram um estado de calma e segurança. Para Kant, seria algo próximo a uma sociedade de nações, onde, após longo período de acomodação, seriam resolvidas as questões externas. No tocante às guerras entre sociedades, o autor as percebe como intenções da natureza em melhorar as sociedades, uma vez que suscitam novas relações entre os Estados, na medida em que desmembram ou mesmo destróem a ordem constituída dos estados antigos. Isto ocorreria até o momento em que as guerras não mais fossem necessárias para a solução de conflitos.

A oitava proposição é uma reafirmação de suas concepções e, principalmente, da colocação da sétima proposição. "A história da espécie humana, no seu conjunto, pode considerar-se como a realização de um plano oculto da natureza, no sentido de estabelecer uma constituição política internamente perfeita - e, em ordem a esse mesmo fim, perfeita também no plano externo, pois esta é a única situação em que a natureza pode desenvolver plenamente na humanidade todas as suas disposições."

Nesta proposição Kant expõe sua compreensão sobre o ponto onde se encontra o desenvolvimento humano. Ele nos coloca que o homem percorreu muito pouco o percurso que a natureza lhe destinou, onde atingirá o momento em que desenvolverá suas disposições naturais em sua plenitude. Isto não nos permite determinar a forma do circuito a ser percorrido e nem tampouco a relação das partes com o todo. Deste aspecto também é inferida a tendência da natureza humana em esperar por uma época mais feliz.

Isto posto, analisa o momento vivenciado por ele, onde percebe que nenhum Estado constituído poderá relacionar-se com outros sem perder poder e influência em relação aos outros. Por conta disso, nenhum Estado poderá descuidar-se de sua cultura interna, a qual serviria talvez de instrumento de coesão do mesmo. Sendo assim, para Kant, a manutenção da finalidade posta pela natureza à humanidade, ou melhor, o progresso humano, encontra-se assegurado pelo jogo de ambição estabelecido entre os Estados na luta por poder e influência. Neste jogo, a liberdade civil não pode mais ser facilmente atacada, sem que haja repercussão em todas as profissões, especialmente o comércio, causandolhes prejuízos, enfraquecendo o poder do Estado nas suas relações externas. A própria relação exterior serve de instrumento coercitivo aos países para que a liberdade seja garantida. Um exemplo disto seria a maior liberdade de religião. Além destes elementos, o impedimento da liberdade individual serviria de amarra a todas as atividades em geral, bem como às forças da comunidade.

Kant também percebe que, muito embora os

\footnotetext{
${ }^{4}$ Sobre este aspecto Kant discorre com maiores detalhes em seu texto "O que é esclarecimento?", no alemão "Beantwortung der Frage: Was ist Aufklärung?", publicado em 05 de dezembro de 1783 .
}

governantes de seu tempo não tenham dinheiro disponível para as instituições de educação pública e outras coisas que representam o que há de melhor no mundo, por gastarem-no com a guerra, este fato não irá impedir os esforços do povo, embora fracos e lentos, de conquistarem educação e chegar "as luzes", ao esclarecimento. ${ }^{4}$

Finalmente coloca que a guerra, pouco a pouco, passará a ser "um empreendimento complicado e duvidoso, de resultados incertos para ambas as partes", bem como "discutível devido às suas consequências para o estado, traduzidas nas sempre crescentes dívidas - uma invenção moderna - cuja liquidação torna-se infindável". Além disso, as guerras tornam-se perturbações políticas aos Estados com os quais o Estado em guerra se relaciona. Por conta disso, estes se oferecem para serem árbitros dos conflitos emergentes. Kant vê nessas atitudes um gérmen da formação de um corpo político de uma situação cosmopolita, onde as disposições naturais da humanidade irão desenvolver-se.

A nona e última proposição fecha o raciocínio ao mesmo tempo que o justifica. "Uma tentativa filosófica para tratar a história universal geral, segundo um plano da natureza que tenha por objetivo a perfeita união política da espécie humana, deve ser considerada como possível e até como vantajosa, para atingir essa finalidade da natureza".

A justificativa às suas argumentações coloca-se na reafirmação da determinação pela natureza dos fins a que se destinam a humanidade, caso não fosse considerada essa hipótese não poderíamos conceber um sistema onde pudéssemos nos representar, ainda que de maneira esquemática; e, a história não seria mais que um "agregado de ações humanas" portanto, esse argumento dá sentido à história.

Partindo da análise da influência que os gregos tiveram sobre os romanos, estes sobre os bárbaros até a destruição dos primeiros, e daí ao momento vivenciado pelo autor, este observa que , sob o ângulo da história política, há uma "marcha regular de melhoramento da constituição política" do continente europeu, que segundo ele "um dia, provavelmente, virá a dar leis a todos os outros". Coloca que , com relação à "constituição política e respectivas leis ou nas relações dos Estados entre si, verificaremos que ambas, pelo que de bom continham, serviram, durante algum tempo, para elevar e glorificar certos povos (e com eles as artes e as ciências)"; apesar disso, como eram imperfeitas, acabaram por ser destruídas, deixando, no entanto, um "gérmen de luzes", para as gerações vindouras.

Por conta disso, faz uma crítica à Igreja, por "louvar a magnificência e a sabedoria da criação no âmbito irracional da natureza, e recomendar a sua contemplação, se a parte da vasta cena da suprema sabedoria, a que contém o fio de tudo isso - a história do gênero humano - continua a ser incessante objeção a essa sabedoria, se a sua vista nos obriga a desviarmos dela os olhos com indignação, e, desesperando de nela encontrar uma finalidade racional perfeita, somos levados a esperá-la somente num outro mundo".

Após, explica que não é sua intenção sugerir que seja posto de lado o estudo da história empírica. Ao contrário, louva a minuciosidade com que é escrita a história de seu 
tempo. Coloca apenas uma reflexão a ser feita: "como compreenderão os nossos vindouros a carga de história que lhes teremos legado ao fim de alguns séculos?'. observa então que a parte que lhes interessará serão os "êxitos e os fracassos dos povos e dos governos no âmbito cosmopolita", sendo que deverá ser levada "em conta a ambição dos governantes e de seus servidores, a fim de lhes apontar o único caminho pelo qual podem deixar uma gloriosa memória para a posteridade" e que constitui um "pequeno motivo" para a tentativa de uma história filosófica.

\section{Freud, o sentimento oceânico, o conceito de Eros e do Instinto de Morte}

A primeira idéia a que o autor irá se referir é que "é impossível fugir à impressão de que as pessoas comumente empregam falsos padrões de avaliação - isto é, de que buscam poder, sucesso e riqueza para elas mesmas e os admiram nos outros, subestimando tudo aquilo que verdadeiramente tem valor na vida" (FREUD,1974:19)

Salienta que qualquer juízo deste tipo desconsidera a variabilidade do mundo humano e sua vida mental.

Um dos primeiros sentimentos que discute a partir deste problema é a religiosidade que, para além da relação que se estabelece com a institucionalização desta pela Igreja, estaria presente nos seres humanos através de uma sensação de eternidade inerente ao ser humano. ${ }^{5}$ Para Freud, no entanto, esta proposição gera uma pequena dificuldade, uma vez que, ele próprio, não percebe em si este sentimento. Daí releva que não é muito fácil lidar cientificamente com sentimentos a não ser através da tentativa de descrevê-los através de seus sinais fisiológicos. Mas, este sentimento de eternidade, também descrito como oceânico desafia este tipo de caracterização, caindo assim no conteúdo ideacional que associa-se ao sentimento.

Poderia ser definido como se tratando de um sentimento "de um vínculo indissolúvel, de ser uno com o mundo externo como um todo."(FREUD,1974:20) O que Freud pretende a partir dessa constatação é verificar se este sentimento está sendo corretamente interpretado e se deve ser encarado como a fonte de toda a necessidade de religião. Para tanto busca na explicação psicanalítica (genética) a resposta para este sentimento.

"Normalmente, não há nada de que possamos estar mais certos do que do sentimento do nosso eu, do nosso próprio ego. O ego nos aparece como algo autônomo e unitário, distintamente demarcado de tudo o mais. Ser essa aparência enganadora - apesar de que, pelo contrário, o ego seja continuado para dentro, sem qualquer delimitação nítida, por uma entidade mental inconsciente que designamos como id, à qual o ego serve como uma espécie de fachada -, configurou uma descoberta efetuada pela primeira vez através

\footnotetext{
5 Esta proposição é colocada à Freud por seu amigo Romain Rolland em carta datada de 5.12.27, logo após a publicação de "The Future of an Illusion".
}

da pesquisa psicanalítica, que, de resto, ainda deve ter muito mais a nos dizer sobre o relacionamento do ego com o id. No sentido do exterior, porém, o ego, de qualquer modo, parece manter linhas de demarcação bem claras e nítidas. Há somente um estado - indiscutivelmente fora do comum, embora não possa ser estigmatizado como patológico - em que ele não se apresenta assim. No auge do sentimento de amor, a fronteira entre ego e objeto ameaça desaparecer. Contra todas as provas de seus sentidos, um homem que se ache enamorado declara que "eu" e "tu" são um só, e está preparado para se conduzir como se isso constituísse um fato."(FREUD,1974:21)

O texto de Freud traz uma discussão sociológica sobre a essência da existência humana organizada da seguinte forma.

A partir da discussão da existência do sentimento de religiosidade Freud introduz uma conclusão que coloca a religiosidade como sendo uma possibilidade de explicação para a finalidade da vida humana. Contudo, considera-a uma visão deformada uma vez que limita a manifestação das perspectivas de vida. ${ }^{6}$

Ao analisar então quais as outras explicações para a finalidade da existência humana, atinge uma das discussões centrais de seu raciocínio, a discussão sobre a felicidade. Esta é colocada como sendo uma outra explicação para o sentido da existência. Os homens viveriam na busca desse objetivo - atingir a felicidade - e assim se explicaria o sentido de sua existência. Contudo, analisa as várias possibilidades de se buscar a felicidade.

Primeiramente define a essência humana entre evitar o desprazer ou realizar a satisfação de seus instintos na busca de prazer.

Segundo o autor "uma criança recém-nascida ainda não distingue o seu ego do mundo externo como fonte de sensações que fluem sobre ela. Aprende gradativamente a fazê-lo, reagindo a diversos estímulos"(FREUD,1974:22) Percebe contudo que o mundo externo proporciona-lhe "sensações de sofrimento e desprazer, cujo afastamento e cuja fuga são impostos pelo princípio do prazer, no exercício de seu irrestrito domínio. Surge então uma tendência a isolar do ego tudo que pode tornar-se fonte de tal desprazer, a lançá-lo para fora e a criar um puro ego em busca de prazer, que sofre o confronto de um "exterior" estranho e ameaçador. As fronteiras desse primitivo ego em busca de prazer não podem fugir a uma retificação através da experiência. Entretanto, algumas das coisas, difíceis de serem abandonadas, por proporcionarem prazer, são, não ego, mas objeto $^{7}$, e certos sofrimentos que se procura extirpar mostram-

\footnotetext{
${ }^{6}$ Segundo Freud "a religião restringe o jogo de escolha e adaptação, impondo igualmente a todos o seu próprio caminho para a aquisição da felicidade e da proteção contra o sofrimento. Sua técnica consiste em depreciar o valor da vida e deformar o quadro do mundo real de maneira delirante - maneira que pressupõe uma intimidação da inteligência. (Op cit p.42)

7 "O ego é contrastado ao "objeto" sob a forma de algo que existe "exteriormente" e que só é forçado a surgir através de uma ação especial" Como na percepção de fontes de excitação identificados como sendo os seus próprios órgãos corporais e em fontes que lhe fogem, lhe são alheios, como o seio da mãe, que reaparecem como resultado de seus gritos de socorro.
} 
se inseparáveis do ego, por causa de sua origem interna. Assim, acaba-se por aprender um processo através do qual, por meio de uma direção deliberada das próprias atividades sensórias e de uma ação muscular apropriada, se pode diferenciar entre o que é interno - ou seja, que pertence ao ego - e o que é externo - ou seja, que emana do mundo externo. Desse modo, dá-se o primeiro passo no sentido da introdução do princípio de realidade, que deve dominar o desenvolvimento futuro. (FREUD, 1974:23)

Freud acrescenta ainda que "a vida, tal como a encontramos, é árdua demais para nós; proporciona-nos muitos sofrimentos, decepções e tarefas impossíveis. A fim de suportá-la, não podemos dispensar as medidas paliativas. Não podemos passar sem construções auxiliares"(...) Existem talvez três medidas deste tipo: derivativos poderosos, que nos fazem extrair luz de nossa desgraça; satisfações substitutivas $^{8}$, que a diminuem; e substâncias tóxicas, que nos tornam insensíveis a ela."(FREUD,1974:31)

A discussão sobre a felicidade apresenta-se sob dois aspectos: um positivo e um negativo. De um lado visando a uma ausência de sofrimento e desprazer, e de outro, visa a experiência de intensos sentimentos de prazer. Contudo, parece que a felicidade do homem não está nos planos da "Criação", pois "o que chamamos de felicidade no sentido mais restrito provém da satisfação ( de preferência repentina) de necessidades represadas em alto grau, sendo por sua natureza, possível apenas como uma manifestação episódica.(...) Assim nossas possibilidades de felicidade sempre são restringidas por nossa própria constituição. Já a infelicidade é muito menos difícil de experimentar. $\mathrm{O}$ sofrimento nos ameaça a partir de três direções: do nosso próprio corpo, condenado à decadência e à dissolução, e que nem mesmo pode dispensar o sofrimento e a ansiedade como sinais de advertência; do mundo externo, que pode voltar-se contra nós com forças de destruição esmagadoras e impiedosas; e, finalmente, de nossos relacionamentos com os outros homens"(FREUD,1974:33)

Para solucionar a questão do sofrimento, Freud nos mostra alguns caminhos seguidos pela humanidade.

Um caminho é a intoxicação, pois "todo sofrimento nada mais é do que sensação; só existe na medida em que sentimos, e só sentimos como conseqüência de certos modos pelos quais nosso organismo está regulado"(FREUD,1974:34)

Pode-se evitar uma parte dos sofrimentos se, agindo sobre o aparelho sensorial, procura-se dominar as fontes internas de nossas necessidades. Por outro lado é possível afastar o sofrimento, deslocando a libido que nosso aparelho mental possibilita, dando-lhe maior flexibilidade. Desta forma, reorienta-se os objetivos instintivos de maneira que eludam a frustração do mundo externo. Para tanto conta com a assistência da sublimação dos instintos. ${ }^{9}$

Um outro caminho seria o isolamento. Segundo Freud

\footnotetext{
${ }^{8}$ Segundo Freud "As satisfações substitutivas, tal como as oferecidas pela arte, são ilusões, em contraste com a realidade; nem por isso, contudo, se revelam menos eficazes psiquicamente, graças ao papel que a fantasia assumiu na vida mental"(op.cit. p.31)

${ }^{9}$ Coloca-se aqui a alegria do artista em criar, a do cientista em solucionar problemas ou descobrir verdades.
}

"um outro processo opera de modo mais enérgico e completo. Considera a realidade como única inimiga e a fonte de todo o sofrimento, com a qual é impossível viver, de maneira que, se quisermos ser de algum modo felizes, temos de romper todas as relações com ela. O eremita rejeita o mundo e não quer saber de tratar com ele. Pode-se porém, fazer mais do que isso; pode-se tentar recriar o mundo, em seu lugar construir um outro mundo, no qual os seus aspectos mais insuportáveis sejam eliminados e substituídos por outros mais adequados a nossos próprios desejos."(FREUD,1974: $38)^{10}$

"A felicidade, no reduzido sentido em que a reconhecemos como possível, constitui um problema de economia da libido do indivíduo. Não existe uma regra de ouro que se aplique a todos: todo homem tem de descobrir por si mesmo de que modo específico ele pode ser salvo. Todos os tipos de diferentes fatores operarão a fim de dirigir sua escolha. É uma questão de quanta satisfação real ele pode esperar obter do mundo externo, de até onde é levado para tornar-se independente dele, e, finalmente, de quanta força sente à sua disposição para alterar o mundo, a fim de adaptá-lo a seus desejos. Nisso, sua constituição psíquica desempenhará papel decisivo, independentemente das circunstâncias externas.'(FREUD,1974:41)

Neste ponto insere a discussão sobre questão da civilização. Por um lado, a civilização seria uma conformação específica na busca da felicidade, uma vez que poderia permitir-nos maiores condições de solucionarmos as questões ligadas à fragilidade de nosso corpos e ao poder superior da natureza. Através da reorientação dos instintos humanos a civilização teria levado a humanidade ao domínio da natureza. Mas, por outro lado, a civilização apesar das conquistas a que levou a humanidade não lhe garante atingir a felicidade almejada.

"Parece certo que não nos sentimos confortáveis na civilização atual, mas é muito difícil formar uma opinião sobre se, e em que grau, os homens de épocas anteriores se sentiram mais felizes e sobre o papel que suas condições culturais desempenharam nessa questão.(...) A felicidade contudo, é algo essencialmente subjetivo.”(FREUD,1974:46)

Freud então procura avaliar a natureza dessa civilização. Descreve-a como 'a soma integral das realizações e regulamentos que distinguem nossas vidas das de outros antepassados animais, e que servem a dois intuitos, a saber: o de proteger os homens contra a natureza e o de ajustar os seus relacionamentos mútuos'(FREUD,1974:47) Descreve como "culturais, todas as atividades e recursos úteis aos homens, por lhes tornarem a terra proveitosa, por protegeremnos contra a violência das forças da natureza, e assim por diante". (FREUD, 1974:47) Na civilização também aparece a valorização da beleza, da limpeza e da ordem. Mais valorizado ainda é "o incentivo em relação às mais elevadas atividades mentais do homem - suas realizações intelectuais, científicas e artísticas - e o papel fundamental que atribui às idéias na vida humana." (FREUD, 1974:52)

\footnotetext{
${ }^{10}$ Aqui podemos inferir a problemática da Utopia, aspecto que Herbert Marcuse retoma em "Eros e Civilização".
} 
Um último aspecto da civilização considerado por Freud é "a maneira pela qual os relacionamentos mútuos dos homens, seus relacionamentos sociais, são regulados - relacionamentos estes que afetam uma pessoa como próximo, como fonte de auxílio, como objeto sexual de outra pessoa, como membro de uma família e de um Estado. Aqui, é particularmente difícil manter-se isento de exigências ideais específicas e perceber aquilo que é civilizado em geral. Talvez possamos começar pela explicação de que o elemento de civilização entra em cena com a primeira tentativa de regular esses relacionamentos sociais. Se essa tentativa não fosse feita, os relacionamentos ficariam sujeitos à vontade arbitrária do indivíduo, o que equivale a dizer que o homem fisicamente mais forte decidiria a respeito deles no sentido de seus próprios interesses e impulsos instintivos ${ }^{11}(. .$.$) A vida humana em comum só se$ torna possível quando se reúne uma maioria mais forte do que qualquer indivíduo isolado e que permanece unida contra todos os indivíduos isolados. O poder dessa comunidade é então estabelecido como "direito', em oposição ao poder do indivíduo, condenado como "força bruta". A substituição do poder do indivíduo pelo poder de uma comunidade constitui o passo decisivo da civilização. Sua essência reside no fato de os membros da comunidade se restringirem em suas possibilidades de satisfação, ao passo que o indivíduo desconhece tais restrições. A primeira exigência da civilização, portanto, é a justiça, ou seja, a garantia de que uma lei, uma vez criada, não será violada em favor de um indivíduo(...) A liberdade do indivíduo não constitui um dom da civilização(...)o desenvolvimento da civilização impõe restrições a ela, e a justiça exige que ninguém fuja a essas restrições. O que se faz sentir numa comunidade humana como desejo de liberdade pode ser sua revolta contra alguma injustiça existente, e desse modo esse desejo pode mostrar-se favorável a um maior desenvolvimento da civilização(...) $\mathrm{O}$ impulso de liberdade, portanto, é dirigido contra formas e exigências específicas da civilização ou contra a civilização em geral(...) Grande parte das lutas da humanidade centralizam-se em torno da tarefa única de encontrar uma acomodação conveniente - isto é, uma acomodação que traga felicidade - entre essa reivindicação do indivíduo e as reivindicações culturais do grupo, e um dos problemas que incide sobre o destino da humanidade é o de saber se tal acomodação pode ser alcançada por meio de alguma forma específica de civilização ou se esse conflito é irreconciliável." (FREUD,1974:53-5)

Logo após o autor faz uma discussão sobre as possibilidades das origens das organizações humanas em comunidades cada vez maiores e sobre como os relacionamentos humanos estão pautados em dois grandes

\footnotetext{
${ }^{11}$ É curioso notar a familiaridade que esta argumentação de Freud tem com o pensamento kantiano. Valeria contudo assinalar que este argumento também serviria como discussão do papel do Estado contemporâneo através até de um viés marxista, haja vista a possibilidade de se entrever na própria legitimação da necessidade de leis que regulamentem a sociedade de um ponto de vista onde os mais fortes as escrevem de acordo com os seus interesses.
}

pólos que se misturam em combinações diversas: Eros, (amor) de um lado e o instinto de Morte (agressividade) de outro.

Eros possibilita ao homem a união com outros homens, impulsionando-os à associação em comunidades. O instinto de morte manifestaria-se como um instinto de agressividade e destrutividade. Ele seria um entrave ao programa da civilização, na medida em que gera a hostilidade de cada um contra todos e a de todos contra cada um. A civilização então, prescinde de mecanismos que inibam ou livre-a da agressividade.

Freud demonstra então, como a formação do superego $^{12}$ contribui para esse controle da agressividade, colocando-a a serviço da civilização. Instaura-se no indivíduo o sentimento de culpa que - criado através da constituição do superego nos indivíduos - mantém a agressividade sob controle na medida em que se volta para o próprio indivíduo.

Freud encerra lembrando que "a questão fatídica para a espécie humana parece (-lhe) ser saber se, e até que ponto, seu desenvolvimento cultural conseguirá dominar a perturbação de sua vida comunal causada pelo instinto humano de agressão e autodestruição.(...) Os homens adquiriram sobre as forças da natureza um tal controle, que, com sua ajuda, não teriam dificuldades em se exterminarem uns aos outros, até o último homem. sabem disso, e é daí que provém grande parte de sua atual inquietação, de sua infelicidade e de sua ansiedade". (FREUD, 1974:108)

\section{KANT E FREUD}

Até o momento foram apresentados os principais eixos dos textos de Kant e Freud que nos servem de base para as argumentações que se seguem.

Em primeiro lugar, há que se ressaltar que os autores possuíam preocupações diferentes que os conduziam em suas reflexões, além da distância histórica que os separa.

Contudo há tanto em Kant quanto em Freud uma linha de raciocínio, um fio condutor que os aproxima.

Kant, partindo de uma preocupação em encontrar o papel da filosofia em relação à história, utiliza-se de uma proposição básica - a sociabilidade insociável da humanidade - para descrever a tensão entre indivíduo e sociedade que lhe serve de fundamento para construir a idéia de progresso da humanidade, que é movido por essa tensão.

Freud por sua vez, preocupado em compreender sua realidade social, descrevendo-a como um momento onde $o$ mal estar se generaliza, também utiliza-se do pressuposto da tensão entre indivíduo e sociedade. A sociabilidade insociável da humanidade reaparece novamente agora através da linguagem psicanalítica.

A contribuição de um autor em relação ao outro está principalmente vinculada ao fato de que Kant procura a generalização que é inerente ao pensamento filosófico,

\footnotetext{
${ }^{12} \mathrm{O}$ superego formaria-se em cada indivíduo através de um processo de internalização da autoridade do "pai" em primeiro plano e depois para as autoridades constituídas na sociedade.
} 
criando um sistema a partir da argumentação sobre os fundamentos da natureza humana. Freud, tenta encontrar a partir de casos específicos observados em seu trabalho como psicanalista, a generalidade que lhe permita construir um sistema que dê conta de explicar os fenômenos isolados, compreendendo assim os aspectos mais primitivos da natureza humana. Ambos os exercícios levam ao mesmo argumento: compreender a natureza humana em uma dicotomia, uma ambigüidade.

Em Kant, essa ambigüidade é percebida como a oposição entre a necessidade da humanidade de se associar para poder desenvolver-se em sua plenitude contraposta a sua tendência animal e egoísta em conduzir-se por si mesmo, que é fruto de sua liberdade de vontade.

Em Freud, a mesma ambigüidade é descrita como o indivíduo sendo movido por dois instintos primevos: Eros e o Instinto de Morte. Eros seria responsável pela união com os outros homens, pela sua necessidade de associação. $\mathrm{O}$ Instinto de Morte seria responsável pela destrutividade e agressividade potenciais dos seres humanos. Contudo o Instinto de Morte serve aos desígnios de Eros no que tange à preservação da espécie e à manutenção da vida. Freud os descreve como instintos que se combinam diferentemente em indivíduos e situações diferentes. Apesar disso, o Instinto de Morte torna-se uma ameaça à associação humana, e principalmente à civilização. Novamente a ambigüidade da natureza humana aparece como uma oposição dicotômica, com dois pólos distintos.

A conseqüência da oposição, da 'sociabilidade insociável" descrita por Kant, ou entre Eros e o Instinto de Morte freudiano, apresenta-se como a criação da necessidade da construção de Leis.

Para Kant as Leis serviriam como o elemento irresistível à essa insociabilidade, uma vez que a liberdade individual seria restringida em detrimento da possibilidade de convivência societária, onde seriam impostos limites à liberdade ao mesmo tempo que seria garantida a sua possibilidade efetiva. As leis descritas através da constituição civil permitiram a criação de uma sociedade onde os seres humanos pudessem desenvolver-se plenamente, desde que sob a égide da Justiça. Esta seria a impossibilidade de um indivíduo isolado constituir-se exceção à lei.

Em Freud as leis aparecem também como meio através do qual a vida humana em comum se torna possível. Isto devido ao fato de que "quando se reúne uma maioria mais forte do que qualquer outro indivíduo isolado, o poder dessa comunidade é então estabelecido como "direito" ". As Leis aparecem como sendo aquilo que é comum a todos os membros da comunidade, e exatamente por isso tornam a comunidade mais forte do que o indivíduo isolado. O elemento novo introduzido por Freud é o fim que é proposto à civilização, ou seja, a busca da felicidade. Neste sentido a constituição justa nada mais seria do que uma acomodação conveniente, que traga felicidade, entre aquilo que o indivíduo reivindica e aquilo que o grupo reivindica.

Outro aspecto relevante, que complementa o pensamento kantiano é a discussão sobre o que Freud considera felicidade. Em primeiro lugar, a felicidade seria o sentido da existência humana. Em segundo lugar, a felicidade apresentaria em dois processos distintos. De um lado a felicidade se daria através da satisfação dos instintos, conquistando prazer. De outro, a felicidade seria conseguida evitando-se o sofrimento e o desprazer. O sofrimento se dá na medida em que o ser humano se encontra em um ambiente hostil, o mundo externo; possui um corpo fadado à decadência e, finalmente ao necessitar relacionar-se com outros indivíduos, precisa resolver os problemas inerentes à esse relacionamento. Os problemas de relacionamento entre os seres humanos são a fonte principal a que se orienta a consecução das leis.

Aqui novamente Freud e kant se aproximam, uma vez que ambos consideram que na civilização tal qual configurada a seus olhos a atividade intelectual, a utilização da razão é a mais alta expressão humana.

Podemos também inferir que há uma similaridade naquilo que para Kant é a necessidade de associar-se aos seres humanos, com o instinto descrito por Freud como Eros. Essas concepções podem completar-se na medida em que sob a égide de Eros os seres humanos tendem à união. Da mesma forma, a insociabilidade descrita por Kant, poderia ser descrita como o indivíduo sob a influência do Instinto de Morte. A liberdade de vontade descrita por Kant como fundada pela própria razão, poderia ser o Instinto de Morte, a agressividade e destrutividade reorientada para uma atomização do indivíduo. Reorientação percebida por Freud no desenvolvimento da civilização. O próprio domínio da natureza é descrito como a reorientação dos instintos, que coloca a agressividade a serviço da civilização.

Vale ressaltar que o desenvolvimento do modo de produção capitalista carece de indivíduos que exercitem um comportamento agressivo em certo sentido, haja vista a competitividade do sistema que busca indivíduos dinâmicos, com iniciativa e arrojados. Qualidades que tem origem diversas da cooperação do trabalho em equipe, etc.

Finalmente, ambos fazem a crítica à religião, mas sob perspectivas diferentes. Kant acusa a Igreja de "louvar a magnificência e a sabedoria da criação no âmbito irracional da natureza". Freud acusa a religião de apresentar uma visão deformada da finalidade da vida humana, limitando a manifestação das perspectivas de vida.

De qualquer forma a sociabilidade insociável dos seres humanos parte de uma idealização filosófica que sustenta o sistema kantiano bem como é fruto das especulações freudianas construídas para dar inteligibilidade aos processos psíquicos inerentes aos seres humanos. 